DOI: $10.34185 / 1991-7848.2019 .01 .12$

УДК 517.9:621.78:669.14

B.I. Цоцко, О.І. Денисенко

\title{
МОДЕЛЮВАННЯ КРИСТАЛІЗАЦІЇ ЛИТИХ ВИРОБІВ В ОБЛАСТІ ОТВОРІВ ЦИЛІНДРИЧНОЇ ФОРМИ
}

\begin{abstract}
Досліди з поверхневим легуванням в області отворів виливок траків гусениць, які широко використовуються в сільськогосподарській та будівельній техніці, показали необхідність точного визначення темпів переміщення кристалізаційного фронту в процесі тверднення поверхневого шару виливок. Досліджувався розподіл температури в системі “ливарний стрижень - розплав" в процесі кристалізації виливків траків в області їх отворів. Поставлена задача про розподіл температури при наявності фазового переходу і про швидкість руху межі розділу фаз в товщі розплаву, що кристалізується, вирішувалась методом кінцевих різниць. Часова залежність переміщення фронту кристалізації одержана в графічній $і$ аналітичній формах. Розрахована швидкість кристалізації поверхневого шару виливків траків в області їх отворів. Визначені швидкості охолодження поверхневих шарів виливків в процесі їх кристалізації.
\end{abstract}

Ключові слова: виливки траків, поверхневе легування виливок, нестаціонарне температурне поле, рівняння теплопровідності, метод кінщевих різниць, швидкість кристалізації, розплав.

\section{Постановка проблеми. Аналіз досліджень і публікацій.}

Керування та оптимізація нестаціонарних температурних полів поверхневого шару конденсованих матеріалів в умовах енергетичної дії на їх поверхню, зокрема імпульсного характеру, можуть бути реалізовані під час лиття виробів, деталей або заготовок.

В процесі кристалізації поверхневий шар виливків піддається імпульсній термічній дії, параметри якої можливо регулювати. Температурне поле і характер його зміни під час кристалізації поверхневого шару виливків визначально впливає на формування властивостей вказаного шару, зокрема на його міцність та інші механічні характеристики. Проблема точного контролю температурного поля поверхневого шару виливків в процесі кристалізації з метою оптимального використання енергії розплавленого металу та керування структуроутворенням даного шару вивчена недостатньо [1, 2].

Відомо, що до ефективних способів підвищення зносостійкості робочих частин деталей машин відноситься їх поверхневе легування. В роботах [3,4] було показано можливість суміщати поверхневе легування із кристалізацією розплаву у ливарній формі.

Використання внутрішньої енергії розплаву для проведення сумісного 3 процесом виготовлення виливків локального насичення їх легуючими елементами 3 метою формування заданих властивостей в заданому місці відноситься до

(c) Цоцко B.I., Денисенко O.I., 2019 
перспективних напрямів хіміко-термічної обробки, які можуть бути узгоджені 3 вимогами до ресурсозберігаючих технологій. В експериментальних дослідженнях поверхневого легування вушок виливків траків [3, 5] був накопичений матеріал щодо обмеження глибини легування зміцнюваного шару. На рис. 1 та рис. 2 наведені фотографії мікроструктур перехідних областей між поверхневим шаром (зліва) та основою (справа), сформованих при поверхневому навуглецюванні та боруванні виливків. На мікрофотографіях проявляється достатньо чітка межа між вказаними шарами виливків.

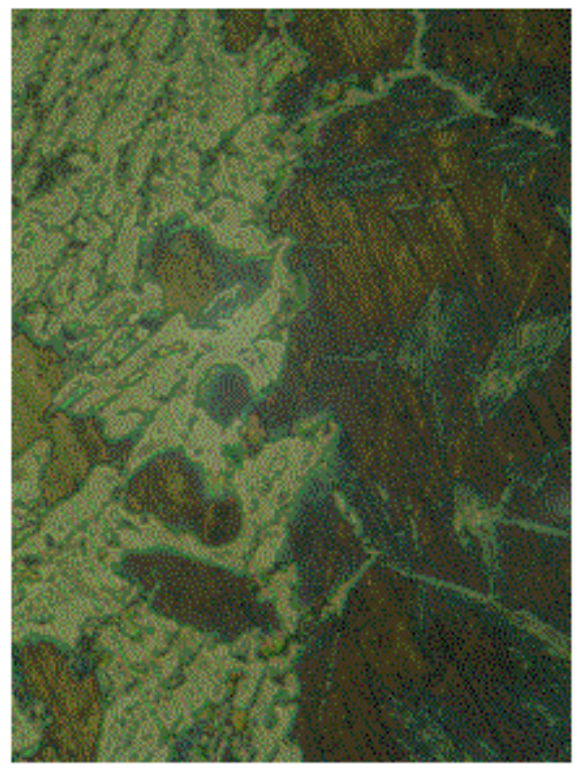

1a $\mathrm{x} 500$

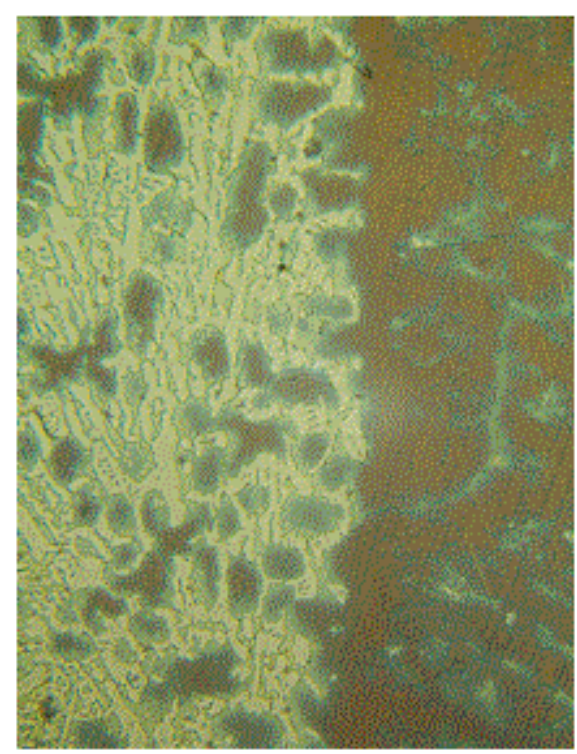

$16 \times 200$

Рисунок 1 - Область розподілу структур навуглецьованого поверхневого шару та основи виливка

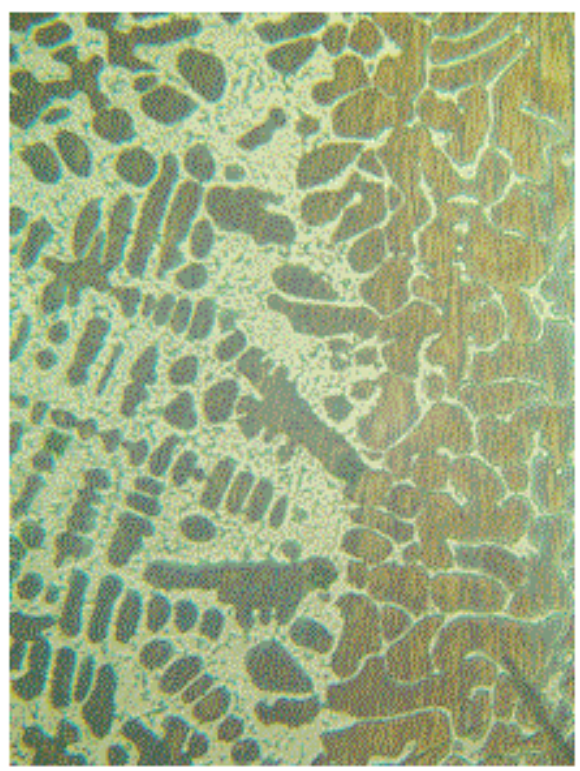

X200

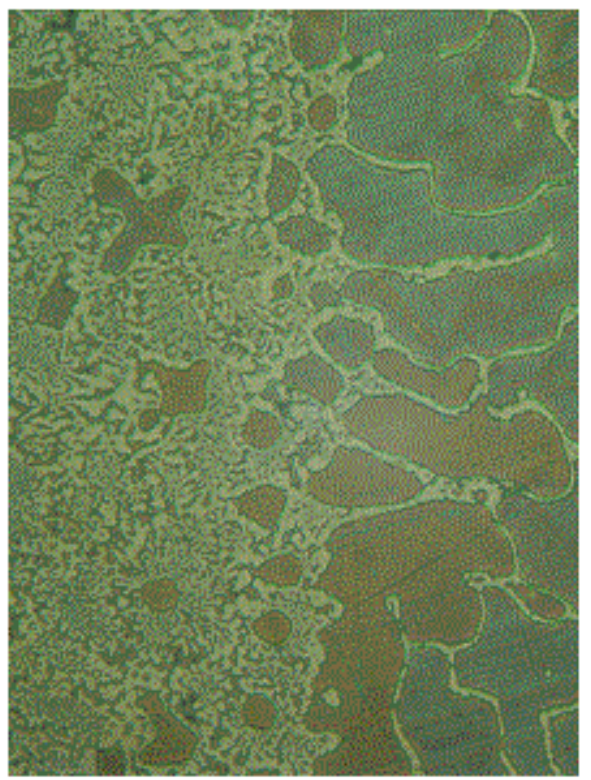

$\mathrm{X} 400$

Рисунок 2 - Область розподілу структур борованого поверхневого шару та основи виливка 
Поряд 3 товщиною легуючої обмазки, дисперсністю та природою насичуючих компонентів визначальним фактором даного обмеження виступає швидкість переміщення кристалізаційного фронту в глибину розплаву, яка є невизначеною.

При переході від однієї фази до іншої макроскопічні характеристики фаз, у тому числі коефіцієнти дифузії, різко змінюються. Границі розподілу фаз відіграють роль бар’єрів для дифузії насичуючих елементів, на подолання яких необхідні додаткові витрати енергії. Визначення та контролювання їх положення може служити важелем у керуванні процесом насичення.

Вплив фазових перетворень на формування дифузійного шару в металах зокрема обгрунтовується в роботі [6].

Область фазового перетворення виступає генератором дефектів, зокрема вакансій, і сприяє прискоренню дифузійного насичення металу домішками. В дослідженні [6] стверджується, що формування дифузійного шару в залізі визначається твердофазними перетвореннями, які протікають в результаті зміни концентрації насичуючих елементів. У наведеній роботі, як і в більшості аналогічних робіт, досліджуються фазові перетворення в межах кристалічного стану. Дифузія в рідкому стані металу протікає на порядок інтенсивніше ніж у твердому стані $[7,8]$. Через те, що швидкість кристалізації розплаву виступає обмежувальним фактором ефективного насичення необхідних ділянок виливків в процесі поверхневого легування, вона потребує точного визначення для заданого об’єкта дослідження.

\section{Мета дослідження}

Дослідження поверхневого легування отворів вушок траків гусениць, які використовуються в сільськогосподарській та будівельній техніці, проведені в умовах виробництва, показали обмеженість товщини легованого шару та порушення неперервності шару в процесі його формування. Було сформульоване припущення про зумовленість даних ефектів рухом фронту кристалізації в глибину розплаву, темпи якого були невідомі.

Метою дослідження було обгрунтування появи вираженої межі між легованим поверхневим шаром виливка траку і його основою та знаходження можливостей підвищення глибини та якості легованого шару виливків траків в області їх отворів. Для досягнення вказаної мети були поставлені задачі моделювання температурного поля поверхневого шару виливків траків в області їх отворів та визначення швидкості переміщення кристалізаційного фронту у вказаній області.

\section{Викладення основного матеріалу дослідження}

Задача про розподіл температури при наявності фазового переходу i про швидкість руху межі розділу фаз всередині розплаву, що кристалізується, зводиться до рішення рівнянь теплопровідності в межах кожної фази з додатковими (початковими та крайовими) умовами та умовами на межі кристалізації, а саме: рівність температур 
контактуючих фаз та енергетична еквівалентність теплових потоків з врахуванням прихованої теплоти фазового перетворення.

Дана задача $є$ задачею Стефана (задачею про фазовий перехід) [9]. У випадку спрощеної одновимірної плоскої моделі системи ливарна форма - рідкий розплав задача достатньо просто розв’язується аналітично методом подібності, що дає наступне алгебраїчне рівняння відносно невідомого $\alpha$ :

$$
\frac{k_{1} c_{c} \exp \left(-\frac{\alpha^{2}}{4 a_{1}^{2}}\right)}{a_{1} \Phi\left(\frac{\alpha}{2 a_{1}}\right)}+\frac{k_{2} c_{p} \exp \left(-\frac{\alpha^{2}}{4 a_{2}^{2}}\right)}{a_{2}\left[1-\Phi\left(\frac{\alpha}{2 a_{2}}\right)\right]}=-\frac{\sqrt{\pi}}{2} \lambda \rho \alpha,
$$

де $\alpha$ - параметр що визначає закон руху межі кристалізації: $\xi=\alpha \sqrt{t}, \mathrm{k}_{1}, \mathrm{a}_{1}^{2} \mathrm{i} \mathrm{k}_{2}, \mathrm{a}_{2}^{2}-$ коефіцієнти теплопровідності i температуропровідності твердої i рідкої фаз відповідно, $\mathrm{c}_{\mathrm{c}}$ та $\mathrm{c}_{\mathrm{p}}$ - початкові температури ливарної форми та розплаву. Ф(s) інтеграл похибок, який часто позначають як $\operatorname{erf}(\mathrm{s})$ :

$$
\Phi(s)=\frac{2}{\sqrt{\pi}} \int_{0}^{s} \exp \left(-y^{2}\right) d y .
$$

Для обчислень використовувалися табличні значення функції похибок Ф(х) згідно 3 даними [10, с. 579, с. 738] i [9, с. 723]. Розв'язок цього трансцендентного рівняння визначає значення параметра $\alpha$.

Чисельний розрахунок параметра швидкості кристалізації $\alpha$ відповідно теплофізичним характеристикам моделі (сталі 110Г13Л), дав наступне значення: $\alpha=0,216 \mathrm{Mm} / \mathrm{c}^{1 / 2}$. Отриманий результат дозволяє оцінити час перебування поверхневого шару виливків у рідкому стані, а отже, -передбачити ефективність і глибину насичення поверхневого шару легуючими елементами у процесі поверхневого легування виливків.

Відповідно до стандарту підприємства СТП 22-033-142-79 (технологічна інструкція з виробництва виливків зі сталі 110Г13Л), максимальна температура розплаву при заливці 3 малого ковша в ливарну форму може досягати $1480{ }^{\circ} \mathrm{C}$, що за рахунок трансформації константи початкової умови с кристалізації $\alpha$ до значення $\alpha=0,154 \mathrm{~mm} / \mathrm{c}^{1 / 2}$. У порівнянні з початковим значенням $\alpha$, маємо його зменшення в 1,4 рази.

На відміну від спрощеної плоскої моделі реальна система ливарна форма - рідкий розплав мала дещо іншу осьову симетрію. Оскільки ливарні стрижні для формування отворів вушок траків мали циліндричну форму і достатню довжину, то задачу Стефана для поверхневого шару вушок виливків траків зручно вирішувати в циліндричних координатах, причому внаслідок симетрії тепловідведення по кутовій i осьовій координатах достатньо обмежитись лише радіальною складовою оператора Лапласа в рівнянні теплопровідності. Тоді при сталості коефіцієнта теплопровідності $\mathrm{k}$ в межах однієї фази рівняння теплопровідності буде мати вигляд: 


$$
c \rho \frac{\partial T}{\partial t}=\frac{1}{r} \frac{\partial}{\partial r}\left(k r \frac{\partial T}{\partial r}\right)=k\left(\frac{\partial^{2} T}{\partial r^{2}}+\frac{1}{r} \frac{\partial T}{\partial r}\right),
$$

а у випадку однорідності параметрів моделі,

$$
\frac{1}{a^{2}} \frac{\partial T}{\partial t}=\frac{\partial^{2} T}{\partial r^{2}}+\frac{1}{r} \frac{\partial T}{\partial r}
$$

де $\mathrm{T}$ - температура, с і $\rho$ - питома теплоємність і густина речовини, $\mathrm{a}^{2}=\mathrm{k} / \mathrm{c} \cdot \rho-$ коефіцієнт температуропровідності фази, $\mathrm{r}$ - відстань, відрахована від осі ливарного стрижня вдовж його радіуса, $\mathrm{t}$ - час.

Додаткові умови для розв'язання задачі Стефана ставились аналогічно плоскій задачі, але додавались деякі нові нюанси. У процесі охолодження і кристалізації розплаву розподіл температури в ливарному стрижні буде змінюватись, але, внаслідок радіальної симетрії системи, градієнт температури на осі стрижня буде постійним i рівним нулю. Серцевина виливка при кристалізації матиме вищу від поверхневих шарів температуру. Передбачалось, що близько середини стінки виливка у розплаві $\left(\mathrm{r}=\mathrm{r}^{\wedge}\right)$ знаходиться також область нульового градієнта. Вказані особливості моделі дозволили перейти до можливості чисельного рішення поставленої задачі.

Рівняння теплопровідності розв'язувалось у системі двох фаз: ливарний стрижень- рідкий розплав, для визначення часу початку кристалізації $\mathrm{t}_{0}$, та у трифазній системі: ливарний стрижень - розплав після кристалізації - рідкий розплав, у подальшій динаміці процесу.

Спроба застосування аналітичного методу для визначення параметра швидкості кристалізації у випадку конечної моделі з осьовою симетрією, що більш точно відображала реальний предмет дослідження - процес кристалізації поверхні виливків в області циліндричних отворів (вушок гусеничних траків), зіткнулась 3 певними труднощами.

Застосування методу подібності для розв’язку вказаних рівнянь [9, с. 263], стандартного підходу для задачі кристалізації, в якому від змінних $\mathrm{r}$ i t переходять до однієї змінної z:

$$
z=\frac{r}{2 \sqrt{t}},(0<\mathrm{z}<\infty)
$$

і 3 рівнянь $з$ частинними похідними (1) і (2) одержують звичайні диференціальні рівняння типу:

$$
-2 z \frac{\partial f}{\partial z}=a^{2}\left(\frac{\partial^{2} f}{\partial z^{2}}+\frac{1}{z} \frac{\partial f}{\partial z}\right),
$$

звідки і знаходять загальне рішення:

$$
f(z)=-C_{1} \int_{z}^{\infty} \frac{1}{z} \exp \left(-\frac{z^{2}}{a^{2}}\right) d z+C_{2}
$$

або 


$$
f(z)=-C_{1} F\left(\frac{z}{a}\right)+C_{2}
$$

вводячи допоміжну функцію $\mathrm{F}(\mathrm{x})$,

$$
F(x)=\int_{x}^{\infty} \frac{1}{x} \exp \left(-x^{2}\right) d x,
$$

призводить до протиріч при визначенні констант інтегрування розв’язку.

Дані протиріччя можна трактувати як неможливість застосування методу подібності для вирішення поставленої задачі. Неприйнятність методу пов'язується 3 асиметрією, неоднорідністю системи по координаті $z=\frac{r}{2 \sqrt{t}}$. На відміну від початкових умов, перетворенням подібності

$$
\mathrm{r}^{\prime}=\mathrm{k} \cdot \mathrm{r}, \mathrm{i} \mathrm{t}^{\prime}=\mathrm{k}^{2} \cdot \mathrm{t},(\mathrm{k} \text { - стала) }
$$

не відповідають граничні умови. Якщо для $r=0$, подібність реалізується, то для умов $\mathrm{r}=\mathrm{r}_{0} \mathrm{i} \mathrm{r}=\mathrm{r}^{\wedge}$ граничні умови змінюються при перетвореннях (5). Причому, зважаючи на конечність значення $\mathrm{r}_{0}$, ситуацію не виправляє навіть перехід $\mathrm{r}^{\wedge} \rightarrow \infty$.

Розв'язок задачі теплопровідності для даної системи можна отримати методом Фур'є у вигляді ряду з умовою сполучення теплових потоків на межі ливарного стрижня та розплаву. Зазначений розв'язок досить громіздкий. Тому, після спроби знаходження аналітичного розв'язку задачі Стефана для досліджуваної системи 3 осьовою симетрією, постає необхідність застосування чисельного методу вирішення поставленого завдання.

Застосуємо для вирішення поставленої задачі чисельний метод - метод кінцевих різниць. Метод кінцевих різниць (метод сіток) є універсальним методом наближеного розв'язку диференціальних рівнянь, в тому числі і рівняння теплопровідності. У зазначеному методі область неперервної зміни аргументів (у нашому випадку r i t) замінюється конечною дискретною множиною точок - вузлів, а похідні, що входять в диференціальне рівняння, замінюються (апроксимуються) відповідними різницевими відношеннями; диференціальне рівняння при цьому замінюється системою алгебраїчних рівнянь (різницевим рівнянням).

Виконаємо стандартне перетворення температури Т в змінну $\mathrm{u}: \mathrm{u}(\mathrm{r}, \mathrm{t})=\mathrm{T}(\mathrm{r}, \mathrm{t})-\mathrm{T}^{*}$, де - температура кристалізації розплаву.

Застосуємо для визначення температур на новому (після шару $\mathrm{t}_{\mathrm{j}}$ ) часовому шарі $t_{j+1}$, де $j$ - номер часового шару, неявну схему обчислення [9, с. 557] або схему 3 випередженням, як стійку схему при довільних часових $\tau$ і просторових $\mathrm{h}$ кроків, на відміну від явної схеми, стійкої лише при певному співвідношенні між ними [9, с. 611]. При цьому диференціальному оператору Lu

$$
L u=\frac{1}{a^{2}} \frac{\partial u}{\partial t}-\left(\frac{\partial^{2} u}{\partial r^{2}}+\frac{1}{r} \frac{\partial u}{\partial r}\right),
$$

ставиться у відповідність різницевий оператор $\mathrm{L}_{\mathrm{h}_{\tau}} \mathrm{u}_{\mathrm{i}, \mathrm{j}+1}$ 


$$
L_{h \tau} u_{i, j+1}=\frac{1}{a^{2}} \frac{u_{i, j+1}-u_{i, j}}{\tau}-\left(\frac{u_{i-1, j+1}-2 u_{i, j+1}+u_{i+1, j+1}}{h^{2}}+\frac{1}{r_{i}} \frac{u_{i+1, j+1}-u_{i, j+1}}{h}\right),
$$

визначений на чотирьохточковому шаблоні $\left(\mathrm{r}_{\mathrm{i}-1}, \mathrm{t}_{\mathrm{j}+1}\right),\left(\mathrm{r}_{\mathrm{i}}, \mathrm{t}_{\mathrm{j}+1}\right),\left(\mathrm{r}_{\mathrm{i}+1}, \mathrm{t}_{\mathrm{j}+1}\right),\left(\mathrm{r}_{\mathrm{i}}, \mathrm{t}_{\mathrm{j}}\right)$, де $\mathrm{i}, \mathrm{j}-$ номера шарів відповідно просторової та часової змінних.

Отже, диференціальному рівнянню

$$
\frac{1}{a^{2}} \frac{\partial u}{\partial t}=\frac{\partial^{2} u}{\partial r^{2}}+\frac{1}{r} \frac{\partial u}{\partial r}
$$

буде відповідати система алгебраїчних рівнянь (різницевих рівнянь):

$$
\frac{1}{a^{2}} \frac{u_{i, j+1}-u_{i, j}}{\tau}=\frac{u_{i-1, j+1}-2 u_{i, j+1}+u_{i+1, j+1}}{h^{2}}+\frac{1}{r_{i}} \frac{u_{i+1, j+1}-u_{i, j+1}}{h}
$$

Виберемо крок просторової координати $\mathrm{h}$ сталим та достатньо малим $\mathrm{y}$ порівнянні з експериментально визначеними $\mathrm{r}_{0}=12 \mathrm{mм} \mathrm{i} \mathrm{r}^{\wedge}=17 \mathrm{~mm}-\mathrm{h}=0,1 \mathrm{mм}$. Тоді $\mathrm{r}_{\mathrm{i}}$ $=\mathrm{i} \cdot \mathrm{h}(\mathrm{i}=0,1, \ldots, 170)$, причому $\mathrm{r}_{0}=\mathrm{r}_{120}, \mathrm{a}^{\wedge}=\mathrm{r}_{170}$.

Постановка різницевої задачі окрім побудови різницевого оператора включає визначення також додаткових умов на сітці (сукупність визначених різницевих рівнянь і додаткових умов називають різницевою схемою).

Початкові умови задають розподіл температури на нульовому часовому шарі при $\mathrm{j}=0$

$$
\begin{gathered}
u_{i, 0}=c_{c}, i=0,1,2, \ldots, 119 ; \\
u_{i, 0}=c_{p}, i=121,122, \ldots, 170 .
\end{gathered}
$$

Температура в 120-му просторовому шарі визначається нижче 3 умови ідеального теплового контакту.

Крайові умови зводяться до рівності пар сусідніх температур для довільних часових шарів j:

$$
\begin{gathered}
\mathrm{u}_{0, \mathrm{j}}=\mathrm{u}_{1, \mathrm{j}} \\
\mathrm{u}_{169, \mathrm{j}}=\mathrm{u}_{170, \mathrm{j}}
\end{gathered}
$$

Умова ідеального теплового контакту в різницевій формі буде мати наступний вид:

$$
k_{0} \frac{u_{120}-u_{119}}{h}=k_{2} \frac{u_{121}-u_{120}}{h}
$$

Неявні схеми для рівняння теплопровідності приводять до системи алгебраїчних рівнянь для значень шуканої функції $\mathrm{u}_{\mathrm{i}, \mathrm{j+1}}$ на новому шарі $\mathrm{t}=\mathrm{t}_{\mathrm{j}+1}$. Вказана система має вид [9, с. 590]

$$
A_{i} u_{i-1}-C_{i} u_{i}+B_{i} u_{i+1}+D_{i}=0,0<\mathrm{i}<\mathrm{N}
$$

(в нашому випадку для стрижня $0<\mathrm{i}<120$ i для розплаву $120<\mathrm{i}<170$ ).

Зіставляючи рівняння (6) і (12), отримаємо вирази для різницевих коефіцієнтів рівняння ливарного стрижня та розплаву:

$$
\begin{array}{llll}
A_{i}=a_{0}{ }^{2} \frac{\tau}{h^{2}}, & B_{i}=a_{0}{ }^{2} \frac{\tau}{h^{2}}\left(1+\frac{1}{i}\right) \ldots C_{i}=a_{0}^{2} \frac{\tau}{h^{2}}\left(2+\frac{1}{i}\right)+1 & D_{i}=T_{c} & 0<\mathrm{i}<120, \\
A_{i}=a_{2}{ }^{2} \frac{\tau}{h^{2}}, & B_{i}=a_{2}{ }^{2} \frac{\tau}{h^{2}}\left(1+\frac{1}{i}\right), & C_{i}=a_{2}{ }^{2} \frac{\tau}{h^{2}}\left(2+\frac{1}{i}\right)+1, \ldots D_{i}=T_{p} & 120<\mathrm{i}<170
\end{array}
$$


Причому, згідно до умови ідеального теплового контакту (11):

$$
\mathrm{A}_{120}=\mathrm{k}_{0}, \mathrm{~B}_{120}=\mathrm{k}_{2}, \mathrm{C}_{120}=\mathrm{k}_{0}+\mathrm{k}_{2}, \mathrm{D}_{120}=0 \text {. }
$$

Для знаходження розв'язку системи (12) крім звичайних методів лінійної алгебри або методів ітерацій застосовують найбільш економічний метод - метод прогонки або метод факторизації [9, с. 591], який враховує спеціальний вигляд матриці системи рівнянь (12). У зазначеному методі розв’язок системи (12) шукають в вигляді:

$$
u_{i}=\alpha_{i+1} u_{i+1}+\beta_{i+1}, \mathrm{i}=0,1,2, \ldots, \mathrm{N}-1
$$

3 (12) і (13) знаходять рекурентні формули для визначення коефіцієнтів $\alpha_{i+1}$ i $\beta_{i+1}$ :

$$
\alpha_{i+1}=\frac{B_{i}}{C_{i}-A_{i} \alpha_{i}}, \beta_{i+1}=\frac{A_{i} \beta_{i}+D_{i}}{C_{i}-A_{i} \alpha_{i}}, \mathrm{i}=1,2, \ldots, \mathrm{N}-1 .
$$

3 умови (9) визначаються значення $\alpha_{1}=1$ i $\beta_{1}=0$. За рекурентним формулами послідовно знаходяться всі інші коефіцієнти. Знаючи значення граничної температури $\mathrm{u}_{\mathrm{N}}$ (обов'язкова умова), за формулою (13) справа наліво - від $\mathrm{i}+1$ до $\mathrm{i}$, визначаються $\mathrm{u}_{\mathrm{N}-1}, \mathrm{u}_{\mathrm{N}-2}, \ldots, \mathrm{u}_{0}$.

Розрахунок за вказаною схемою не дав бажаного результату, оскільки висока температура в зоні розплаву "тримала" температуру поверхневого шару виливка i перешкоджала процесу кристалізації.

Був застосований інший варіант формул прогонки [9, с.592], коли використовується розв'язок системи (12) у вигляді

$$
u_{i+1}=\alpha_{i+1} u_{i}+\beta_{i+1}, \mathrm{i}=0,1,2, \ldots, \mathrm{N}-1 \text {, }
$$

де

$$
\alpha_{i}=\frac{A_{i}}{C_{i}-B_{i} \alpha_{i+1}}, \beta_{i+1}=\frac{B_{i} \beta_{i+1}+D_{i}}{C_{i}-B_{i} \alpha_{i+1}}, \mathrm{i}=1,2, \ldots, \mathrm{N}-1 .
$$

При цьому опорною температурою $\epsilon$ температура $\mathrm{u}_{0}$, а $і$ ї задання визначає розрахунок всіх інших температур у вузлах. 3 умови (10) визначалися $\alpha_{\mathrm{N}}=1 \mathrm{i}$ $\beta_{\mathrm{N}}=0$, а потім послідовно знаходилися всі інші коефіцієнти $\alpha_{\mathrm{i}}$ та $\beta_{\mathrm{i}}$ системи (14). За

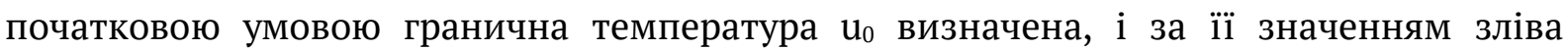
направо (від $\mathrm{i}$ до $\mathrm{i}+1)$ визначаються $\mathrm{u}_{1}, \mathrm{u}_{2}, \ldots, \mathrm{u}_{\mathrm{N}}$. Для наступних часових шарів, згідно 3 умовою (9), в якості температури $\mathrm{u}_{0}$ бралася температура $\mathrm{u}_{1} 3$ попереднього часового шару. Тим самим усувалась невизначеність граничної температури на осі ливарного стрижня і здійснювалося гнучке налаштування температурного градієнта осі на нульове значення.

Після досягнення температури кристалізації на поверхні контакту ливарного стрижня з розплавом в ньому починає формуватися кристалічна фаза.

Вирази для різницевих коефіцієнтів у вузлах ливарного стрижня i у вузлах розплаву залишаться колишніми, тільки значення $\mathrm{D}_{\mathrm{i}}$ в кожному новому часовому шарі будуть замінюватися попередніми значеннями температури в цих вузлах. Різницеві коефіцієнти вузлів розплаву, крім того, будуть починатися не з колишнього номера вузла $(\mathrm{i}=121)$, а з наступних номерів - $\mathrm{i}=122,123, \ldots$ 
На границі ливарного стрижня з застиглим розплавом умова рівності теплових потоків в різницевої формі прийме вигляд (вважається, що фронт кристалізації вже досяг 121-го вузла):

$$
k_{0} \frac{u_{120}-u_{119}}{h}=k_{1} \frac{u_{121}-u_{120}}{h}
$$

або

$$
k_{0}\left(u_{120}-u_{119}\right)=k_{1}\left(u_{121}-u_{120}\right) .
$$

Різницеве рівняння, відповідне умові фазового переходу на границі розділу твердого та рідкого розплаву у момент досягнення фронтом кристалізації першого після поверхні контакту зі стрижнем вузла кристалічної фази (121-го в наскрізній нумерації) матиме вигляд:

або

$$
k_{1} \frac{u_{121}-u_{120}}{h}=k_{2} \frac{u_{122}-u_{121}}{h}+\lambda \rho \frac{h}{\tau}
$$

$$
k_{1}\left(u_{121}-u_{120}\right)=k_{2}\left(u_{122}-u_{121}\right)+\lambda \rho \frac{h^{2}}{\tau} .
$$

Відповідно до рівнянь (15) і (16), різницеві коефіцієнти виразу (12), для вузлів, що поділяють фази, приймуть вигляд:

$$
\begin{gathered}
\mathrm{A}_{120}=\mathrm{k}_{0}, \mathrm{~B}_{120}=\mathrm{k}_{1}, \mathrm{C}_{120}=\mathrm{k}_{0}+\mathrm{k}_{1}, \mathrm{D}_{120}=0 ; \quad \mathrm{i} \\
\mathrm{A}_{121}=\mathrm{k}_{1}, \mathrm{~B}_{121}=\mathrm{k}_{2}, \mathrm{C}_{121}=\mathrm{k}_{1}+\mathrm{k}_{2}, \mathrm{D}_{121}=\lambda \rho \mathrm{h}^{2} / \tau .
\end{gathered}
$$

Використовуючи зворотну прогонку, варіюємо значенням часового кроку $\tau$ так щоб розрахункова температура в 121-му вузлі досягла температури кристалізації $\left(\mathrm{T}^{*}=1360{ }^{\circ} \mathrm{C}\right.$ або $\left.\mathrm{u}=0\right)$ і фіксуємо вказаний проміжок часу.

При подальшому розрахунку руху фронту кристалізації додаткова умова на поверхні затвердіння (16) зазнає зсуву від вузла до вузла в напрямку до $\mathrm{r}^{\wedge}$. Різницеві коефіцієнти проміжних між $\mathrm{r}_{0} \mathrm{i} \mathrm{r}^{*}$ вузлів знаходяться аналогічно, відповідно до різницевого рівняння (6), в якому коефіцієнт температуро-провідності $\mathrm{a}^{2}$ приймає значення коефіцієнта температуропровідності кристалічної фази $\mathrm{a}^{2}=\mathrm{a}_{1}^{2}$, тобто за формулами:

$$
A_{i}=a_{1}^{2} \frac{\tau}{h^{2}}, \quad B_{i}=a_{1}^{2} \frac{\tau}{h^{2}}\left(2+\frac{1}{i}\right), \ldots C_{i}=a_{1}^{2} \frac{\tau}{h^{2}}\left(2+\frac{1}{i}\right)+1, \quad D_{i}=u_{i, j-1} \quad 120<\mathrm{i}<170,
$$

де $\mathrm{u}_{\mathrm{i}, \mathrm{j}-1}$ - температура в $\mathrm{i}$-му просторовому шарі в попередньому до розрахун-кового (jго) часовому шарі. Запропонований метод розв'язку був апробований на конференціях, наприклад - [12].

\section{Результати дослідження}

Кристалізація розплаву, що вступив в тепловий контакт з ливарним стрижнем, починається не миттєво, а через деякий час $\mathrm{t}_{0}$, упродовж якого розплав на поверхні контакту $\mathrm{r}=\mathrm{r}_{0}$, де $\mathrm{r}_{0}-$ радіус ливарного стрижня ( $\left.\mathrm{r}_{0}=12 \mathrm{Mм}\right)$, охолодиться до температури кристалізації. Упродовж рішення початкової (двохфазної задачі) був розрахований час $\mathrm{t}_{0}$ досягнення температури кристалізації на 
межі ливарного стрижня 3 розплавом: $t_{0}=2,48$ мс. Розподіл температури по найближчим розрахунковим точкам біля вказаної межі $r=r_{0}$ наведений на рис. 3 . Температура ливарного стрижня $\mathrm{T}_{\mathrm{c}}$ та температура розплаву в момент заливки у форму $\mathrm{T}_{\mathrm{p}}$ відповідно становили $20^{\circ} \mathrm{C}$ та $1420^{\circ} \mathrm{C}$.

Змінюючи часовий крок $\tau$, так щоб розрахункова температура в кожному наступному вузлі досягала температури кристалізації $\mathrm{T}^{*}=1360^{\circ} \mathrm{C}$, визначалось переміщення фронту тверднення.

Чисельні значення коефіцієнтів $\mathrm{k}_{0}=0,33 \mathrm{BT} /(\mathrm{M} \cdot \mathrm{K}), \quad \mathrm{k}_{1}=26 \mathrm{BT} /(\mathrm{M} \cdot \mathrm{K})$, $\mathrm{k}_{2}=9 \mathrm{BT} /(\mathrm{M} \cdot \mathrm{K}), \lambda=270 \cdot 10^{3}$ Дж/кг, $\rho=7,3 \cdot 10^{3} \mathrm{~K} / \mathrm{M}^{3}$, а також розрахункові величини $\mathrm{a}_{0}^{2}=\mathrm{k}_{0}$ $/\left(\mathrm{c}_{0} \cdot \rho_{0}\right)=0,265 \cdot 10^{-6} \quad \mathrm{M}^{2} / \mathrm{c}, \quad \mathrm{a}_{1}{ }^{2}=\mathrm{k}_{1} \quad /\left(\mathrm{c}_{1} \cdot \rho_{1}\right) \quad=5,24 \cdot 10^{-6} \quad \mathrm{M}^{2} / \mathrm{c}$, $\mathrm{a}_{2}^{2}=\mathrm{k}_{2} /\left(\mathrm{c}_{2} \cdot \rho_{2}\right)=1,56 \cdot 10^{-6} \mathrm{M}^{2} / \mathrm{c} \mathrm{визначались} \mathrm{за} \mathrm{довідниковими} \mathrm{даними.}$

Рішення основної (трифазної) задачі дало наступні результати. На рис. 4 наведено розподіл температур в системі ливарний стрижень $\left(0<\mathrm{r}<\mathrm{r}_{0}\right)$ - застиглий розплав $\left(\mathrm{r}_{0}<\mathrm{r}<\mathrm{r}^{*}\right)$ - рідкий розплав $\left(\mathrm{r}^{*}<\mathrm{r}<\mathrm{r}^{\wedge}\right)$ у різні моменти часу $\mathrm{t}$ після початку кристалізації, при значеннях параметрів $\mathrm{r}_{0}=12 \mathrm{mM} \mathrm{i}$ $\mathrm{r}^{\wedge}=17$ мм. Координата $\mathrm{r} *$ дорівнює відповідно 12,3 мм $(\mathrm{t}=3,28 \mathrm{c}) ; 12,6 \mathrm{мм}$ $(\mathrm{t}=11,08 \mathrm{c}) ; 13,2 \mathrm{мм}(\mathrm{t}=27,83 \mathrm{c}) ; 14,4 \mathrm{мм}(\mathrm{t}=88,23 \mathrm{c})$.

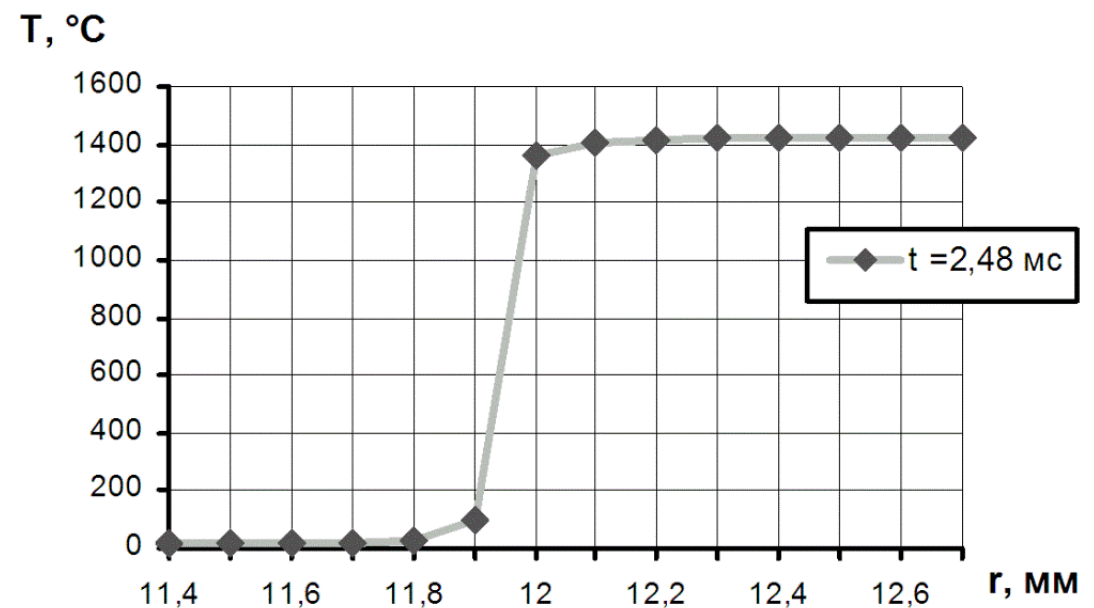

Рисунок 3 - Розподіл температури поблизу межі ливарного стрижня з розплавом в момент $\mathrm{t}_{0}=2,48 \mathrm{Mc}$

Залежність переміщення фронту кристалізації $\Delta \mathrm{r}^{*}=\mathrm{r}^{*}-\mathrm{r}_{0}$ від часу $\Delta t$, відрахованого від моменту досягнення температури кристалізації на границі ливарного стрижня та розплаву $\left(\Delta \mathrm{t}=\mathrm{t}-\mathrm{t}_{0}\right)$, в кожному зазначеному випадку показана на рис. 5. Оскільки $\mathrm{t}_{0}=2,48$ мс досить малий інтервал, то можна вважати $\Delta \mathrm{t}=\mathrm{t}$. Реальна середина стінки виливка траку в області вушок $\left(\mathrm{r}^{\wedge}\right)$ відхилялась від середнього значення 17 мм \pm 1 мм. 


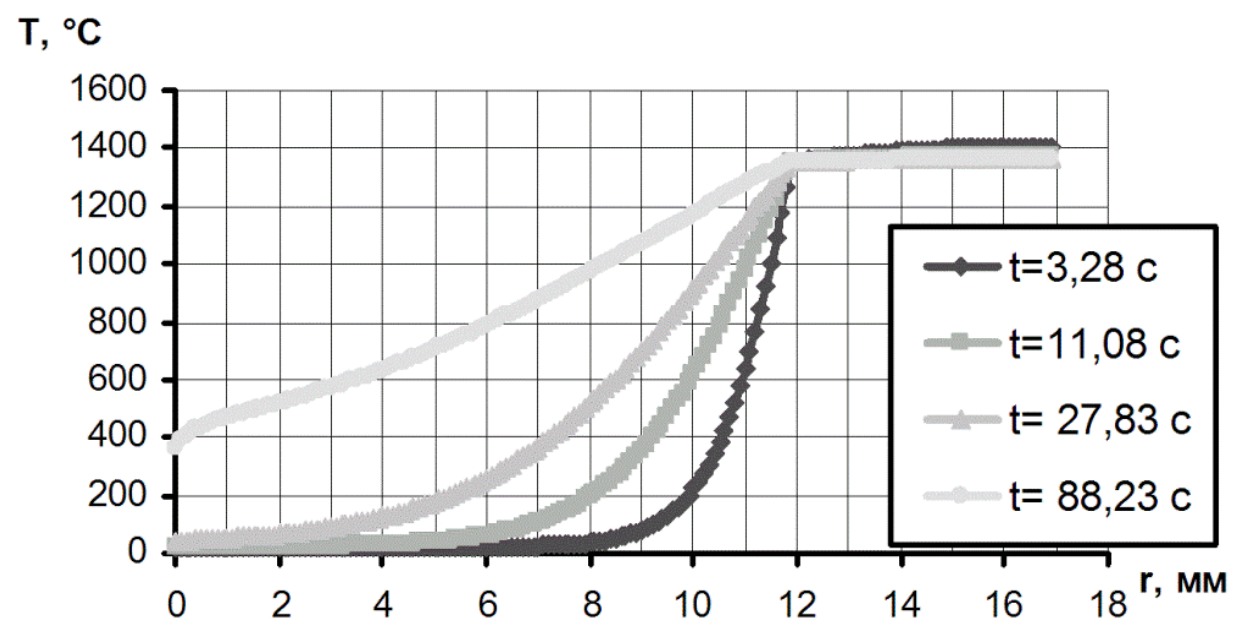

Рисунок 4 - Розподіл температур в системі ливарний стрижень - поверхневий шар виливка в різні моменти часу після початку кристалізації

Вирівнювання даних чисельного експерименту за степеневою кривою способом найменших квадратів [11, с. 319,325$]$ дає наступну емпіричну формулу зв'язку між $\Delta \mathrm{r}^{*}$ i $\Delta \mathrm{t}$ :

$$
\Delta r^{*}=\alpha \Delta t^{\beta}
$$

Для розмірностей $\left[\Delta \mathrm{r}^{*}\right]=$ мм $\mathrm{i}[\Delta \mathrm{t}]=\mathrm{c}$, коефіцієнти рівняння (17) дорівнюють відповідно: $\alpha=0,149$ і $\beta=0,623$ для $\mathrm{r}^{\wedge}=17$ мм.

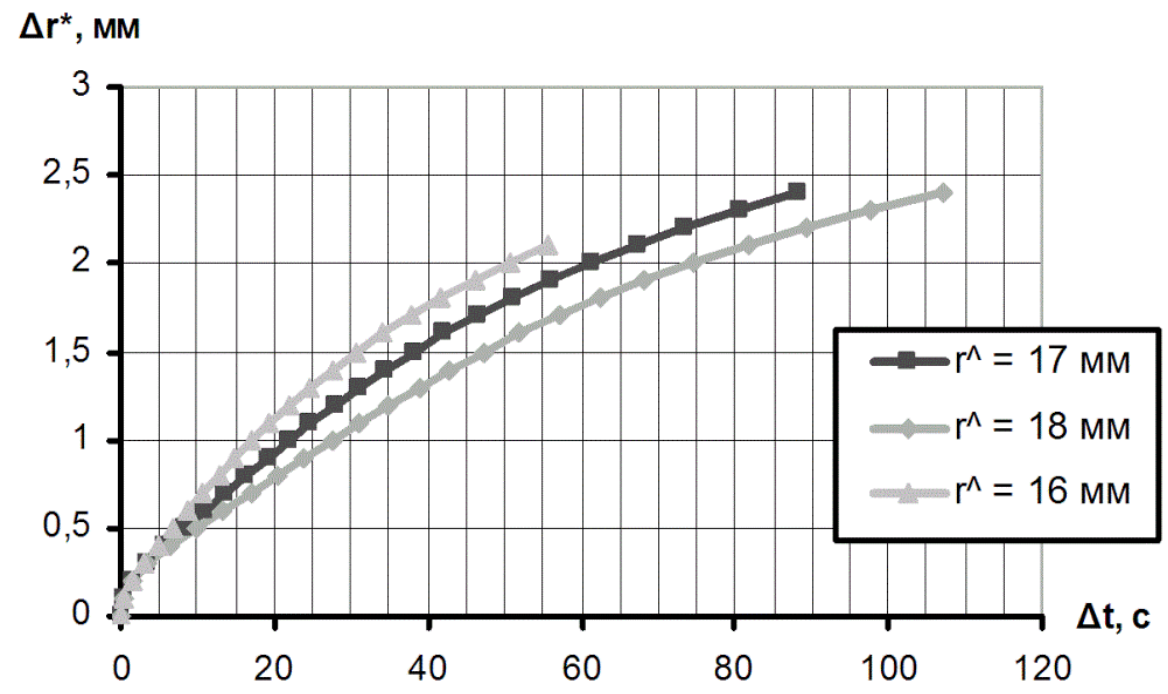

Рисунок 5 - Переміщення фронту кристалізації розплаву в залежності від різних значень параметра $\mathrm{r}^{\wedge}$

Відмінність величини $\beta$ від значення $\beta=1 / 2$ [9, с. 255,263$]$ зумовлено порушенням однорідності граничних умов порівняно 3 напівнескінченною моделлю i некоректністю застосування методу подібності до вирішення поставленої задачі. Відхилення показника ступеня $\beta$ в формулі (17) від значення $1 / 2$ можна трактувати як зміну з часом сталої $\alpha$ в законі руху кристалізаційного фронту при $\beta=1 / 2$.

$$
\Delta r^{*}=\alpha(t) \sqrt{t}
$$


Вказаний тезис підтверджується стабілізацією параметра $\alpha \approx 0,25$ в рівнянні (17) при достатньому віддаленні фронту кристалізації від поверхні виливка, коли температура в зоні нульового градієнта $\left(\mathrm{r}=\mathrm{r}^{\wedge}\right)$ практично не змінюється, наближаючись до температури кристалізації розплаву.

Існування вираженої межі між поверхневим легованим шаром та основою виливка (рис. 1-2) підтверджує, що ефективне насичення поверхневого шару відбувається саме в зоні розплаву. Швидкість кристалізації детермінує процес насичення, а кристалізаційний фронт фіксує результат. Згідно рис. 4 часова експозиція інтенсивного насичення дослідженої моделі знаходиться в межах $\approx 20$ с.

Порівняння розподілів температури в затверділому поверхневому шарі, отриманих шляхом чисельного розрахунку на базі одновимірної моделі кристалізації та на моделі з осьовою симетрією, що відповідала параметрам реальної системи, дало наступні результати.

На рис. 6 наведено розподіл температури в поверхневому затверділому шарі виливка при переміщенні фронту кристалізації на відстань $\mathrm{x}_{0}=1,2$ мм від поверхні виливка. Відзначається незначне запізнення швидкості кристалізації плоскої моделі, в порівнянні 3 циліндричною моделлю, для еквівалентного зміщення фронту кристалізації на 0,1 мм.

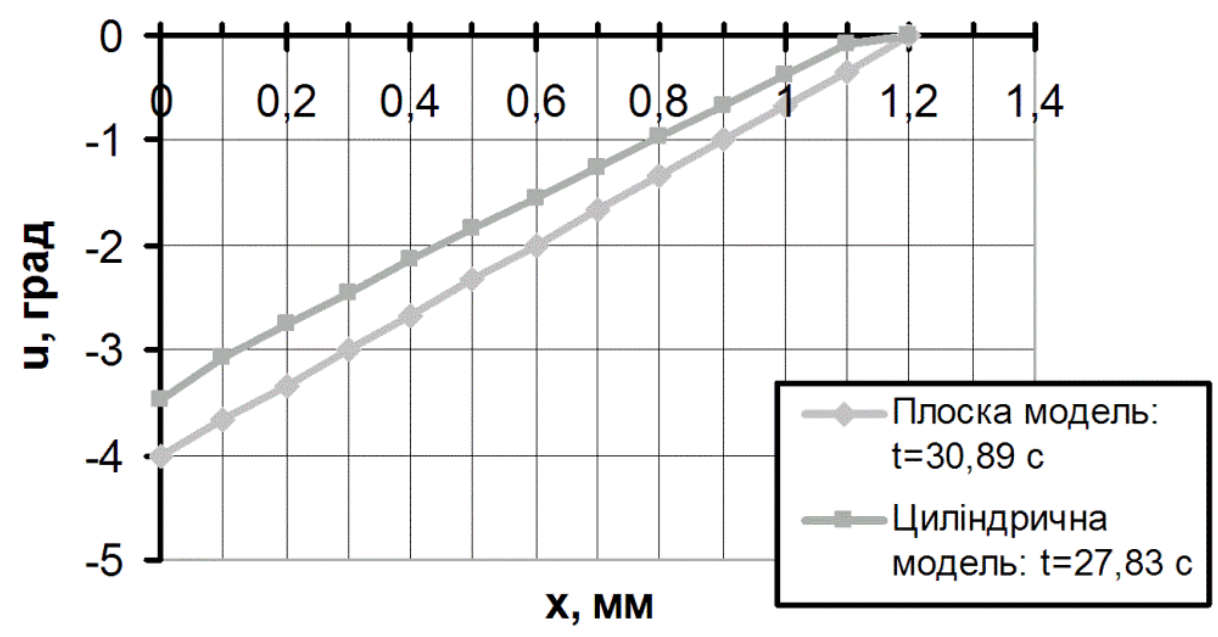

Рисунок 6 - Розподіл температур в поверхневому шарі виливка після кристалізації

На рис. 7 наведено розширений розподіл температури у вказаних моделях, який охоплює додатковий шар прилеглого до фронту кристалізації розплаву. Відзначимо тенденцію збільшення розбіжності в температурах при відхиленні від зони кристалізаційного фронту, особливо в області розплаву. 


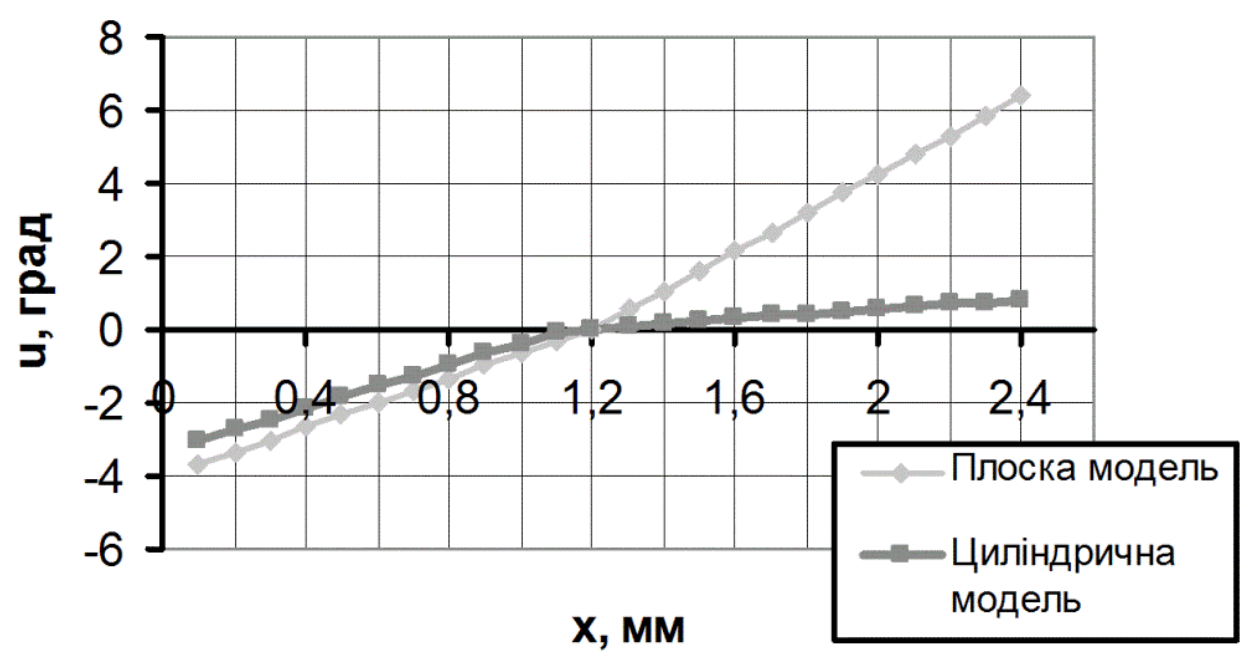

Рисунок 7 - Розподіл температур в поверхневому шарі виливка в процесі кристалізації

По розрахунковим точкам температурного поля поверхневого шару вушок в процесі кристалізації була досліджена швидкість охолодження поверхневого шару. Максимальна швидкість охолодження $24200{ }^{\circ} \mathrm{C} / \mathrm{c}$ розвивається на поверхні виливка в початковий, докристалізаційний період, на глибині 0,1 мм, 0,2 мм, 0,3 мм вона становить $5550{ }^{\circ} \mathrm{C} / \mathrm{c}, 1270{ }^{\circ} \mathrm{C} / \mathrm{c}, 291^{\circ} \mathrm{C} / \mathrm{c}$ відповідно. У більш віддалених від поверхні шарах максимум швидкості охолодження настає з деяким запізненням і затуханням. Можна констатувати утворення температурної хвилі, що рухається від поверхні в глибину виливка з швидкістю 0,5 мм/с.

Одержані швидкості охолодження поверхневих шарів виливків в процесі кристалізації дозволяють оцінити величину механічних напруг і темпи зміни коефіцієнтів дифузії насичуючих елементів при поверхневому легуванні виливків.

\section{Висновки}

Чисельно-аналітичним моделюванням нестаціонарного температурного поля поверхневого шару виливків траків в області їх отворів було встановлено швидкості охолодження поверхневого шару в процесі кристалізації та швидкість переміщення кристалізаційного фронту. Одержані параметри дозволяють оцінити час перебування визначеного поверхневого шару виливків у рідкому стані i, як наслідок, передбачити ефективність суміщення поверхневого легування 3 процесом кристалізації та розрахувати глибину насичення легуючим елементом поверхневого шару.

\section{ЛITЕРАТУРА}

1. Таран Ю.Н. Количественное исследование текстуры роста кристаллов цементита эвтектического чугуна / Ю.Н. Таран, Г. М. Воробьев, О.А. Петрова // Известия АН СССР. Металлы. № 1. - 1987. - с. 62-66.

2. А. с. 1766609 СССР, МКИ ${ }^{3}$ В 22 D 27/04. Устройство для получения чугунных отливок с отбеленным рабочим слоем / Г. М. Воробьев, О. А. Петрова, В. И. Цоцко (СССР) . опубл. в 1992. - Бюл. № 37.

3. Tsotsko V. I. Application of casting surface alloying for hardening surface of track pin holes / V. I. Tsotsko, A. I. Burya, V. I. Shemavnev, G. M. Vorobyev // 2nd International 
Conference "Research and Development in Mechanical Industry" (RaDMI 2002), 01-04 September 2002, Vrnjačka Banja, Yugoslavia. - V. 2. - S. 1100-1105.

4. А. с. 1540937 СССР, МКИ В 22 D 27/20. Способ легирования поверхности проушин в отливках траков / Г. М. Воробьев, В. И. Цоцко (СССР) . - опубл. в 1990. - Бюл. № 5.

5. Цоцко В. І. Легування поверхневого шару ливарної заготовки в процесі лиття / В. І. Цоцко, Б. Г. Пелешенко, П. І. Мельник. - Металознавство та обробка металів. № 2. - 2009. - C. 27-30.

6. Мельник П. І. Дифузійні процеси та твердофазні перетворення в металах і сплавах /

П. І. Мельник, Б. К. Остафійчук, С. І. Сидоренко. - Івано-Франківськ: Плай, 1999. - 220 c.

7. Лепинских Б. М. Диффузия элементов в жидких металлах группы железа / Б. М. Лепинских, А. В. Кайбичев, Ю. А. Савельев. - М. : Наука, 1974. - 192 с.

8. Бокштейн Б. С. Диффузия в металлах / Б. С. Бокштейн. - М.: Металлур-гия, 1978. 248 c.

9. Тихонов А.Н. Уравнения математической физики / А. Н. Тихонов, А.А. Самарский. - М.: Наука, 1972. - 736 с.

10. Корн Г. Справочник по математике / Г. Корн, Т. Корн. - М.: Наука, 1974. - 832 с.

11. Маркович Э. С. Курс высшей математики с элементами теории вероятнос-тей и математической статистики. М.:Высшая школа, 1972. - 480 с.

12. Tsotsko V. I. Simulation of crystallization of the surface layer of track castings in the region of holes / V. I. Tsotsko, B. G. Peleshenko // International Conference Differential Equations, Mathematical Physics and Applications, October 17-19, 2017, Cherkasy, Ukraine / Book of Abstracts. - Vinnitsa: Vasyl' Stus Donetsk National University, 2017. - P. 144-145.

\section{REFERENCES}

1. Taran Yu. N. Kolichestvennoe issledovanie teksturyi rosta kristallov tsementita evtekticheskogo chuguna / Yu. N. Taran, G. M. Vorobev, O. A. Petrova // Izvestiya AN SSSR. Metallyi. \# 1. - 1987. - S. 62-66.

2. A. s. 1766609 SSSR, MKI ${ }^{3}$ B 22 D 27/04. Ustroystvo dlya polucheniya chugunnyih otlivok s otbelennyim rabochim sloem / G. M. Vorobev, O. A. Petrova, V. I. Tsotsko (SSSR) . - opubl. v 1992. - Byul. \# 37.

3. Tsotsko V. I. Application of casting surface alloying for hardening surface of track pin holes / V. I. Tsotsko, A. I. Burya, V. I. Shemavnev, G. M. Vorobyev // 2nd International Conference "Research and Development in Mechanical Industry" (RaDMI 2002), 01-04 September 2002, Vrnjačka Banja, Yugoslavia. - V. 2. - S. 1100-1105.

4. A. s. 1540937 SSSR, MKI ${ }^{3}$ B 22 D 27/20. Sposob legirovaniya poverhnosti proushin v otlivkah trakov / G. M. Vorobev, V. I. Tsotsko (SSSR) . - opubl. v 1990. - Byul. \# 5.

5. Tsotsko V. I. Lehuvannia poverkhnevoho sharu lyvarnoi zahotovky v protsesi lyttia / V. I. Tsotsko, B. H. Peleshenko, P. I. Melnyk. - Metaloznavstvo ta obrobka metaliv. - № 2. 2009. - S. 27-30.

6. Melnyk P. I. Dyfuziini protsesy ta tverdofazni peretvorennia v metalakh i splavakh / P. I. Melnyk, B. K. Ostafiichuk, S. I. Sydorenko. - Ivano-Frankivsk: Plai, 1999. - 220 s. 
7. Lepinskih B. M. Diffuziya elementov v zhidkih metallah gruppyi zheleza / B. M. Lepinskih, A. V. Kaybichev, Yu. A. Savelev. - M.: Nauka, 1974. - 192 s.

8. Bokshteyn B. S. Diffuziya v metallah / B. S. Bokshteyn. - M.: Metallurgiya, 1978. - 248 s.

9. Tihonov A. N. Uravneniya matematicheskoy fiziki / A. N. Tihonov, A. A. Samarskiy. - M.: Nauka, 1972. - $736 \mathrm{~s}$.

10. Korn G. Spravochnik po matematike / G. Korn, T. Korn. - M.: Nauka, 1974. - 832 s.

11. Markovich E. S. Kurs vyisshey matematiki s elementami teorii veroyatnostey i matematicheskoy statistiki. M.: Vyisshaya shkola, 1972. - $480 \mathrm{~s}$.

12. Tsotsko V. I. Simulation of crystallization of the surface layer of track castings in the region of holes / V. I. Tsotsko, B. G. Peleshenko // International Conference Differential Equations, Mathematical Physics and Applications, October 17-19, 2017, Cherkasy, Ukraine / Book of Abstracts. - Vinnitsa: Vasyl' Stus Donetsk National University, 2017. - P. 144-145.

Received 10.01.19

\section{SIMULATION OF CRYSTALLIZATION OF CAST PRODUCTS IN THE AREA OF CYLINDRICAL HOLES}

One of the methods of intensive high-energy processing of metal products is their surface alloying. In the process of surface doping, the saturation of the surface layer of the metal by the necessary, for example, strengthening, components and thermal effects on the metal occurs. When surface doping of castings, firstly, high-temperature heat fluxes are formed, which provide high efficiency of doping, secondly, by using the energy of the melt, significant savings are achieved in the energy costs required for heat treatment.

Experiments on surface doping of track tracks in the area of their holes, which are widely used in agricultural and construction equipment, have shown the need to accurately determine the rate of movement of the crystallization front in the process of hardening the surface layer of castings. In connection with the technical difficulties of experimental research, there was a need for numerical-analytical modeling of this process. . The features of the model under study, first of all, are its axial symmetry, which leads to a significant deviation of the expected results in comparison with the classical flat models.

The dynamics of temperature distribution in the system "casting core - melt" was studied in the process of crystallization of tracks in the area of their holes. The problem of temperature distribution in the presence of a phase transition and the speed of movement of the interface between the phases within a crystallizing melt was solved by the finite difference method using an implicit scheme for drawing up a system of difference equations. The time dependence of the crystallization front displacement in graphical and analytical forms was obtained. The rate of crystallization of the surface layer of tracks in the area of their holes was calculated. The cooling rates of the surface layers of the castings during their crystallization are determined.

The calculated crystallization rate of the metal in the area of the tracks of the castings of tracks allows to determine the time of active dissolution of the alloying components in the surface layer of the castings and to predict the required dispersion of fractions of saturating components in the composition of the alloying coating of the cores.

Keywords: casting of tracks, surface doping of castings, non-stationary temperature field, heat equation, finite difference method, crystallization rate, melt. 


\section{МОДЕЛИРОВАНИЕ КРИСТАЛЛИЗАЦИИ ЛИТЫХ ИЗДЕЛИЙ В ОБЛАСТИ ОТВЕРСТИЙ ЦИЛИНДРИЧЕСКОЙ ФОРМЫ}

Опыты с поверхностным легированием в области отверстий отливок траков гусениц, которые широко используются в сельскохозяйственной и строительной технике, показали необходимость точного определения темпов перемещения кристаллизационного фронта в процессе затвердевания поверхностного слоя отливки. Исследовалось распределение температуры в системе "литейный стержень - расплав" в процессе кристаллизации отливок траков в области их отверстий. Поставленная задача о распределении температуры при наличии фазового перехода и о скорости движения границы раздела фаз в толще кристаллизирующегося расплава ешалась методом конечных разностей. Временная зависимость перемещения фронта кристаллизации полученна в графической и аналитической формах. Рассчитана скорость кристаллизации поверхностного слоя отливок траков в области их отверстий. Определены скорости охлаждения поверхностных слоев отливок в процессе их кристаллизации.

Ключевые слова: отливки траков, поверхностное легирование отливок, нестационарное температурное поле, уравнения теплопроводности, метод конечных разностей, скорость кристаллизации, расплав.

Денисенко Олександр Іванович - кандидат технічних наук, доцент, керівник центру дистанційного навчання Національної металургійної академії України.

Denisenko Alexandr Ivanovich - candidate of technical sciences, associate professor, head of the distance learning center of the National Metallurgical Academy of Ukraine.

Цоцко Віталій Іванович - старший викладач кафедри вищої математики та фізики інженерно-технологічного факультету Дніпровського державного аграрноекономічного університету.

Tsotsko Vitalij Ivanovich - Senior Lecturer of the Department of Higher Mathematics and Physics of the Faculty of Engineering and Technology of the Dnipro State Agrarian and Economic University. 